\title{
Coexistence of Chronic Complications among Diabetic Patients at Nigist Eleni Mohammed Memorial Hospital, Hossana, South Ethiopia
}

\author{
Dawit Jember Tesfaye ${ }^{1}$, Fasil Tessema², Mohammed Taha² \\ ${ }^{1}$ Department of Clinical Nursing, Hossana Health Science College, Hossana, Ethiopia \\ ${ }^{2}$ Department of Epidemiology, College of Public Health and Medical Science, Jimma University, Jimma, Ethiopia \\ Email: devanhijember@gmail.com, alazarfasil@yahoo.com, tahamohammed2009@gmail.com
}

Received 8 November 2014; revised 14 December 2014; accepted 31 December 2014

Copyright (C) 2015 by authors and OALib.

This work is licensed under the Creative Commons Attribution International License (CC BY). http://creativecommons.org/licenses/by/4.0/ (c) (i) Open Access

\begin{abstract}
Background: Chronic complications reduce quality of life, increases diabetes related mortality and overburden the public health services. This study aims to assess the prevalence of chronic complications and its associated factors among diabetic patients at Nigist Eleni Mohammed Memorial Hospital, Hossana, South Ethiopia. Method and Materials: We conducted a hospital based cross-sectional study. A simple random sampling technique was used to select 266 participants from the follow up clinic of the hospital. Data were collected using semi structured questionnaire, weight, height, waist and hip circumference measurements and patients chart review. Descriptive statistics was used to describe the study variable. Bivariate and multivariate logistic regression analysis was used to identify factors associated with chronic diabetic complications. Result: Out of 247 diabetic subjects, $114(46.2 \%)$ were found to have at least one chronic complication that included, hypertension $59(23.9 \%)$, diabetes related eye disease $29(11.7 \%)$, neuropathy $25(10.1 \%)$ and nephropathy $16(6.5 \%)$. Compared to age group 15 - 29 there was higher risk of chronic complications for those who were in age groups $45-64,[\mathrm{AOR}=2.50,(95 \% \mathrm{CI}):(1.20,5.22)]$ and $\geq 65$ years, $[A O R=7.18,(95 \% \mathrm{CI}):(2.10,24.87)]$. Duration of diabetes $>10$ years $[\mathrm{AOR}=2.87,(95 \% \mathrm{CI}):(1.20$, $6.88)]$, and not performing self-monitoring of blood glucose, $[\mathrm{AOR}=15.22,(95 \% \mathrm{CI}):(3.07,75.48)]$ were also strongly associated with chronic complications of diabetes mellitus. Conclusion and Recommendation: Considerable number of diabetic participants in this study area had at least one chronic complication. Attention should be given to older diabetic patients and longer diabetic duration. Diabetic education should focus on health benefit of self-monitoring of blood glucose.
\end{abstract}

\section{Keywords}

Diabetes Mellitus, Chronic Complication, Risk Factors

Subject Areas: Public Health

How to cite this paper: Tesfaye, D.J., Tessema, F. and Taha, M. (2015) Coexistence of Chronic Complications among Diabetic Patients at Nigist Eleni Mohammed Memorial Hospital, Hossana, South Ethiopia. Open Access Library Journal, 2: e1218. http://dx.doi.org/10.4236/oalib.1101218 


\section{Introduction}

The worldwide prevalence of diabetes mellitus (DM) estimated to grow to 366 million to 440 million by 2030, with three-quarters of patients with diabetes living in low-income countries and the greatest relative increases will occur in the Middle Eastern Crescent, sub-Saharan Africa (SSA), and India [1]. In 2010, 12.1 million people were estimated to be living with diabetes in Africa, and this is projected to increase to 23.9 million by 2030 [2]. The incidence and prevalence of diabetes mellitus in general Ethiopian population is unknown [3]. However, limited studies have shown the rise in prevalence of diabetes.

The chronic complications of diabetes mellitus affect many organ systems and are responsible for majority of morbidity and mortality associated with the disease [4]. In Sub Saharan Africa, proportions of patients with chronic diabetic complications ranged from 7\% - 63\% for retinopathy, $27 \%$ - $66 \%$ for neuropathy and $10 \%$ - 83\% for micro albuminuria [5]. In Ethiopia also higher proportion of diabetic patients has been shown to be affected by chronic complications [6]-[11].

Consequently, the total cost to manage chronic complications in diabetics far outweighs the cost of effective primary and secondary prevention [12]. In addition, chronic complications affect working-age diabetes which leads to low productivity and then contribute to poverty [13]. In a country with lowest per capita income like Ethiopia, chronic complications pose even worse threat from economic standpoint [12].

Various factors including type II diabetes mellitus [8], duration of diabetes [14], poorly controlled cases and dyslipidemia [13] have been known to increase the risk of chronic complications. In China the prevalence of chronic diabetic complications have been reported to increase with age [14] [15]. Different studies indicated that Being female [16] and overweight, obesity [14] and central obesity [17] are risk factors for chronic complications. Thus management of these risk factors could reduce the risk of chronic complications. Furthermore, continuous medical care and ongoing self-management education are required to prevent and control diabetic complications [5].

At Nigist Eleni Mohammed Memorial Hospital, South Ethiopia (i.e. the study area) chronic complication of diabetes and its associated factors were not studied. The hospital 2013 nine month report showed that DM is the six leading causes of admission and ten top cause of chronic disease morbidity [18]. Thus, the rising prevalence of diabetes may increase the prevalence of chronic complications. Subsequently, chronic complication of diabetes results in increase diabetes mortality, permanent disability and incur heavy burden to health care system [12] [19]. A study conducted in Yekatit 12 hospital showed that chronic complications were responsible for $60.6 \%$ of diabetic death [19] and in Tikur anbesa and St. Paul's hospitals 28\% of deaths among diabetic admission were attributed to chronic complications [20].

The combined effects of diabetes and its chronic complication place further strain on the patient, family and overburden public health services. Therefore, we aimed to assess the prevalence of chronic complications and its associated factors among diabetic patients attending chronic care follow up clinic of Nigist Eleni Mohammed Memorial Hospital, Hossana, South Ethiopia.

\section{Methods and Materials}

\subsection{Study Design and Setting}

This hospital based cross sectional study was conducted from October 7-November 5/2013 at Nigist Eleni Mohammed Memorial Hospital, which is located in Hossana town, South Ethiopia. The Hospital serves for about 1,506,733 million populations. The chronic care follow up clinic of the hospital provide services for a total of481 diabetic patients and to congestive heart failure, hypertensive and asthmatic patients for five days a week (i.e. Monday to Friday). On a monthly interval insulin is provided free of charge for insulin treated diabetic patients and the follow up service is provided by medical doctors.

\subsection{Selection of the Study Participants}

The source populations were all diabetic patients registered and has a follow up visit in the hospital chronic care clinic. The study population were diabetic patients whose age is $>15$ years. The sample size was calculated using single population proportion with finite correction formula, considering the proportion of diabetic patients with chronic complication to be $52.5 \%$ [8], a precision of $5 \%$ and with $95 \%$ confidence level. After adding $20 \%$ for non-response, an overall sample size of 266 was obtained. The study participants were selected using computer 
generated simple random sampling technique based on the patients' card number.

\subsection{Data Collection}

Data was collected using semi structured questionnaire, weight, height, hip and waist circumference measurements and patient chart review. The questionnaire was initially prepared in English and it was translated to Amharic for the purpose of data collection. Then the Amharic questionnaire was back translated to English to check for any inconsistency in the meaning of the words and/or concepts. Before data collection training was provided for data collectors and supervisor on the objective, process of data collection and how to take anthropometric measurements. Pretesting of the instrument was made before the commencement of the actual data collection. Data were collected from selected diabetic patients during the follow up visit to the clinic (i.e. Exit interview) in a separate room. The data collectors were supervised on daily basis for completeness and consistency of the filled questionnaire.

Weight was measured two times with minimum clothing and no shoe using Seca electronic weighing scale in kilogram $(\mathrm{kg})$ to the nearest $0.1 \mathrm{~kg}$. The weight scale was checked against zero reading before weighing every diabetic participant. Height was measured in a standing position in centimeter to the nearest 1 centimeter $(\mathrm{cm})$. Waist circumference was measured at a level midway between lower rib margin and iliac crest on a horizontal plane around the body [21]. Tape meter was used to measure both waist and hip circumference. Patient's chart was reviewed for chronic diabetic complications, fasting blood sugar and types of diabetes. Two trained nurses and one supervisor were involved in the data collection.

\subsection{Measurements}

Diabetes self-care practice was assessed using Summary Diabetes Self-Care Activity (SDSCA) measure [22] which contains 11 items on diet, exercise, medication, self-monitoring of blood glucose, foot care and cigarette smoking. Each question measures diabetes self-care activity during last seven days on a continuous scale from 0 to 7 days. Dietary adequacy was measured based on a response to four diet questions and calculated out of 7 . When the participants has an average of $4-7$ days to dietary questions were coded as having adequate dietary practice and $<4$ day was coded as inadequate dietary practice. Exercise was considered adequate if the participants participate in at least 30 minutes of physical activity for 3 or more days or participate in a specific exercise session during last seven days otherwise it was classified as inadequate exercise. Participants who were performed Self-Monitoring of Blood glucose at his/her home at least once during last seven days were coded "Yes". Medication adequacy was assessed as follows. When participants were taking all his recommended insulin injections or diabetes pills during last 7 days was considered adequate medication intake otherwise inadequate. Concerning foot care, participants who has an average of $4-7$ days to foot care questions was coded adequate foot care and $<4$ days was considered inadequate foot care.

Participants whose waist to hip circumference ratio $\geq 90$ centimeter for male and $\geq 85$ centimeter for female were considered centrally obese [21]. Body mass index of the participants were calculated by dividing the participants weight to height square. And it was coded underweight when the body mass index was $<18.5 \mathrm{~kg} / \mathrm{m}^{2}$, overweight $25-29.9 \mathrm{~kg} / \mathrm{m}^{2}$, Obese $\geq 30 \mathrm{~kg} / \mathrm{m}^{2}$ and normal body mass index $18.5-24.9 \mathrm{~kg} / \mathrm{m}^{2}$.

A diabetic patient with at least one microvascular complication (i.e. Retinopathy, neuropathy and nephropathy) or macro vascular complication (i.e. coronary heart disease, peripheral vascular disease and hypertension) or non-vascular complication (i.e. skin infection, foot ulcer and impotence) was coded as having chronic complication. A diabetic patient who had no any documented chronic complications listed above was coded "No chronic complication".

\subsection{Data Analysis}

After data collection each questionnaire was checked for completeness. Data was entered in to and analyzed using SPSS version 16 computer software. Descriptive statistics like frequency tables, graphs and descriptive summaries were used to describe the study variables. Chi-square test was used to see the existence of association between dependent and each independent variable. Those variables with p-value of $<0.25$ in bivariate analysis were entered in to backward multiple binary logistic regression model. P-value $<0.05$ was considered statistically significant. Interactions between variables were checked. 


\subsection{Ethical Consideration}

Before data collection, ethical clearance was obtained from ethical clearance committee of Jimma University, college of public health and medical science. A formal letter of cooperation was submitted to Nigist Eleni Mohammed Memorial Hospital. Verbal informed consent was obtained from each study participants.

\section{Result}

Out of 266 sampled subjects, 247 participated making the response rate 92.9\%. The rest 19 (7.1\%) were excluded because they gave incomplete information. Of all participants, 147 (59.5\%) were male. Mean age ( \pm SD) was $43.5( \pm 13.5)$ years ranging between 17 and 71 years. Majority of the participants $111(44.9 \%)$ were in the age range of 45 - 64 years. More than three fourth 188 (76.1\%) were Hadiya by ethnicity, 170 (70.9\%) were married and 70 (28.3\%) were illiterate. Urban residence accounted for 155 (62.8\%) and 88 (35.6\%) of the patient were employed (Table 1).

\subsection{Diabetic Self-Care Practice}

Two hundred and fourteen (86.6\%) were found to have adequate dietary practice. Majority 191 (77.3\%) and 56 (22.7) had inadequate exercise and medication intake respectively. Only 17 (6.9\%) were performed self-monitoring of blood glucose and 237 (96\%) had inadequate foot care practice. Cigarette smoking accounted for 6 (2.4\%) of diabetic participants (Table 2).

\subsection{Blood Glucose and Anthropometric Measurements}

Of the participants, 159 (64.4\%) were found to have uncontrolled glycemic level. Normal waist to hip ratio were found in 81 (32.8\%) and the rest were centrally obese. Of all diabetic participants 121 (49\%) had normal body mass index and the rest 20 (8.1\%), 94 (38.1\%) and 12 (4.8\%) were underweight, overweight and obese respectively (Table 3).

\subsection{Prevalence of Chronic Complications}

Of the total 247 diabetic participants, more than half 133 (53.8\%) had no documented chronic complications and 114 (46.2\%) had at least one chronic complications.

Regarding the type of complications, proportion of diabetic eye disease, neuropathy and nephropathy were 29 (11.7\%), 25 (10.1\%) and 16 (6.5\%) respectively. Out of the total participants 59 (23.9\%) had hypertension. Impotence was documented in $3(1.2 \%)$ of diabetic patients. One $(0.4 \%)$ of the participants had Foot ulcer (Figure 1).

Of the factors entered into multivariable logistic regression model only patient's age, duration of diabetes and self-monitoring of blood glucose (SMBG) showed significant association with chronic complications among diabetic patients.

Diabetic patients between age 45 - 64 were 2.50 times more likely [AOR $=2.50,95 \%$ CI: $(1.20,5.20)$ ] to have chronic complications than age 15 - 29. Diabetic patients with age $\geq 65$ years were 7.18 times more likely [AOR $=7.18,95 \% \mathrm{CI}:(2.10,24.87)]$ to have chronic complications than those between age 15 - 29. Diabetics with $>10$ year duration of diabetes were 2.87 times more likely to have chronic complications [AOR $=2.87$, 95\% CI: $(1.20,6.88)]$ than $<5$ years duration of diabetes. Additionally, Diabetic patients who did not monitored their blood sugar level were 15.22 times more likely [AOR = 15.22, 95\% CI: $(3.07,75.48)$ ] having chronic complications than those who monitored their blood sugar level (Table 4).

\section{Discussions}

This study demonstrated that the overall prevalence of chronic complications among diabetic patients was 46.2\%. Our finding is lower than a study done in Jimma University Hospital, Ethiopia 52.5\% [8], while the prevalence of chronic complications obtained in this study was higher than other studies conducted in Menilik II hospital, Ethiopia 37.45\% [23], Netherland 20.9\% [24] and USA 19.7\% [25]. The possible explanation for this discrepancy might be associated with quality of care, difference in sample size, study area and/or purpose of the study. 
Table 1. Background characteristics of diabetic participants by chronic complication at Nigist Eleni Mohammed Memorial Hospital, Hossana, South Ethiopia, 2013.

\begin{tabular}{|c|c|c|c|c|c|}
\hline \multicolumn{6}{|c|}{ Chronic complication } \\
\hline \multicolumn{2}{|l|}{ Characteristics } & Yes N (\%) & No N (\%) & Total N (\%) & COR" (95\% CI) \\
\hline \multicolumn{6}{|l|}{ Sex } \\
\hline & Male & $67(45.6)$ & $80(54.4)$ & 147 (59.5) & 1 \\
\hline & Female & $47(47)$ & $53(53)$ & $100(40.5)$ & $1.06(0.64,1.76)$ \\
\hline \multicolumn{6}{|l|}{ Age } \\
\hline & $15-29$ & $17(32.1)$ & $36(67.9)$ & $53(21.7)$ & 1 \\
\hline & $30-44$ & $11(20.4)$ & $43(79.6)$ & 54 (21.9) & $0.54(0.23,1.30)$ \\
\hline & $45-64$ & $63(56.8)$ & $48(43.2)$ & $111(44.9)$ & $2.78(1.40,5.53)^{\ddagger}$ \\
\hline & $\geq 65$ & $23(79.3)$ & $6(20.7)$ & $29(11.7)$ & $8.12(2.79,23.61)^{\ddagger}$ \\
\hline \multicolumn{6}{|l|}{ Ethnicity } \\
\hline & Hadiya & $87(46.3)$ & $101(53.7)$ & $188(76.1)$ & 1 \\
\hline & Others ${ }^{*}$ & $27(45.8)$ & $32(54.2)$ & 59 (23.9) & $0.98(0.55,1.76)$ \\
\hline \multicolumn{6}{|l|}{ Marital status } \\
\hline & Married & $34(47.2)$ & $38(52.8)$ & 175 (70.9) & 1 \\
\hline & Not married ${ }^{* *}$ & $80(45.7)$ & 95 (54.3) & $72(29.1)$ & $0.94(0.54,1.63)$ \\
\hline \multicolumn{6}{|l|}{ Educational status } \\
\hline & Illiterate & $36(51.4)$ & $34(48.6)$ & $70(28.3)$ & 1 \\
\hline & Elementary & 27 (39.7) & $41(60.3)$ & 68 (27.3) & $0.62(0.31,1.22)$ \\
\hline & Secondary ${ }^{* * * *}$ & $51(46.8)$ & $58(53.2)$ & 109 (44.1) & $0.83(0.46,1.56)$ \\
\hline \multicolumn{6}{|l|}{ Place of residence } \\
\hline & Urban & $74(47.7)$ & $81(52.3)$ & $155(62.8)$ & 1 \\
\hline & Rural & $40(43.5)$ & $52(56.5)$ & $92(37.2)$ & $0.84(0.50,1.42)$ \\
\hline \multicolumn{6}{|l|}{ Occupation } \\
\hline & Employed & 43 (48.9) & $45(51.1)$ & 88 (35.6) & 1 \\
\hline & Housewife & $23(53.5)$ & $20(46.5)$ & 43 (17.1) & $0.83(0.40,1.73)$ \\
\hline & Student & 18 (64.3) & $10(35.7)$ & $28(11.3)$ & $0.53(0.22,1.28)$ \\
\hline & Merchant & $19(65.5)$ & $10(34.5)$ & 29 (11.7) & $0.50(0.21,1.20)$ \\
\hline & Farmer & $24(57.1)$ & 18 (42.9) & 42 (17) & $0.72(0.34,1.50)$ \\
\hline & Daily worker & $6(35.3)$ & $11(61.7)$ & 17 (6.9) & $1.75(0.59,5.15)$ \\
\hline \multicolumn{6}{|l|}{ Family history } \\
\hline & Yes & $30(48.4)$ & $32(51.6)$ & $62(25.1)$ & 1 \\
\hline & No & 103 (55.7) & $82(44.3)$ & 185 (74.9) & $1.34(0.72,2.48)$ \\
\hline \multicolumn{6}{|l|}{ Duration of diabetes (In year) } \\
\hline & $<5$ & $52(34.7)$ & $98(65.3)$ & $150(60.7)$ & 1 \\
\hline & $5-10$ & $32(57.1)$ & $24(42.9)$ & $56(22.7)$ & $2.51(1.34,4.70)^{\ddagger}$ \\
\hline & $>10$ & $30(73.2)$ & $11(26.8)$ & $41(16.6)$ & $5.14(2.38,11.08)^{\ddagger}$ \\
\hline \multicolumn{6}{|l|}{ Type of diabetes } \\
\hline & Type I & 19 (33.9) & $37(66.1)$ & $56(22.7)$ & 1 \\
\hline & Type II & 95 (49.7) & $96(50.3)$ & 191 (77.3) & $1.93(1.04,3.59)^{\ddagger}$ \\
\hline
\end{tabular}

*Amhara, Guraghe, Kembata, Silte, Wolayta and/or Tigre; ${ }^{* * *} 7$ - 12 grade, diploma and/or degree; ${ }^{\dagger}$ P-Value $<0.05$; "Crude odd ratio. 
Table 2. Self-care practice characteristics of diabetic participants at Nigist Eleni Mohammed Memorial Hospital, Hossana, South Ethiopia, 2013.

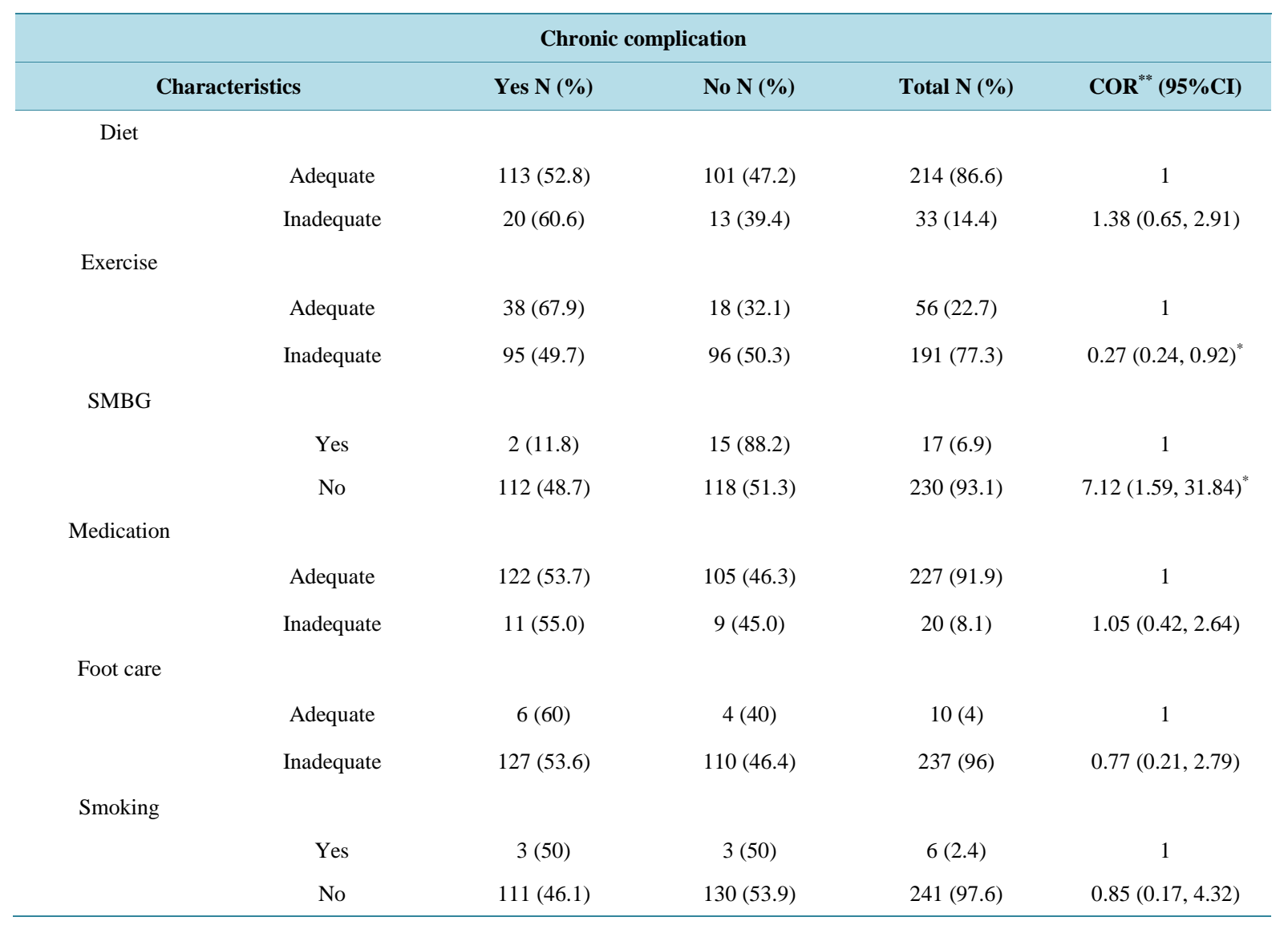

${ }^{*}$ P-value $<0.05 ;{ }^{* *}$ Crude odd ratio.

Table 3. Blood glucose and anthropometric measurements of diabetic participants at Nigist Eleni Mohammed Memorial Hospital, Hossana, South Ethiopia, 2013.

\begin{tabular}{|c|c|c|c|c|}
\hline \multicolumn{5}{|c|}{ Chronic complication } \\
\hline Measurement & \multirow{2}{*}{ Yes N (\%) } & \multirow[t]{2}{*}{ No N (\%) } & \multirow[t]{2}{*}{ Total N (\%) } & \multirow[t]{2}{*}{$\mathrm{COR}^{*}(95 \% \mathrm{CI})$} \\
\hline Fasting blood sugar & & & & \\
\hline$<126 \mathrm{mg} / \mathrm{dl}$ & $39(44.3)$ & 49 (55.7) & 88 (35.6) & 1 \\
\hline$\geq 126 \mathrm{mg} / \mathrm{dl}$ & $75(47.2)$ & $84(52.8)$ & $159(64.4)$ & $1.12(0.67,1.89)$ \\
\hline \multicolumn{5}{|l|}{ Waist to hip ratio } \\
\hline Normal & 32 (39.5) & 49 (60.5) & $81(32.8)$ & 1 \\
\hline Central obesity & 32 (39.5) & $84(50.6)$ & $166(67.2)$ & $1.49(0.87,2.56)$ \\
\hline \multicolumn{5}{|l|}{ Body mass index } \\
\hline Underweight & $11(55)$ & $9(45)$ & $20(8.1)$ & $1.74(0.67,4.49)$ \\
\hline Normal & $50(41.3)$ & $71(58.7)$ & $121(49.0)$ & 1 \\
\hline Overweight & 45 (47.9) & $49(52.1)$ & 94 (38.1) & $1.30(0.76,2.24)$ \\
\hline Obese & $8(66.7)$ & $4(33.3)$ & $12(4.8)$ & $2.84(0.81,9.95)$ \\
\hline
\end{tabular}

${ }^{*}$ Crude odd ratio. 
Table 4. Multivariable logistic regression model predicting chronic complications among diabetic patients at Nigist Eleni Mohammed Memorial Hospital, Hossana, South Ethiopia, 2013.

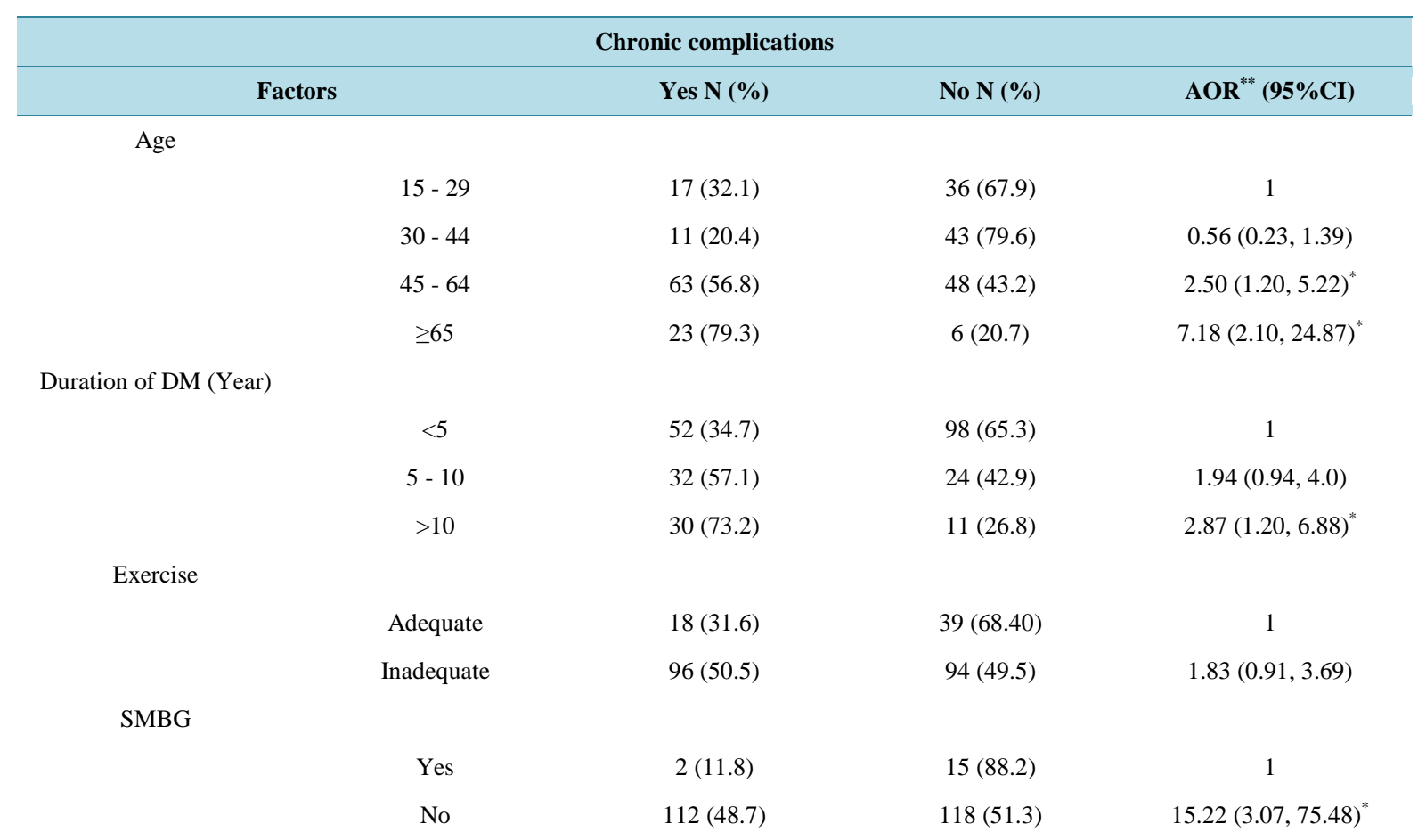

${ }^{*}$ P-value $<0.05 ;{ }^{* *}$ Adjusted odd ratio.

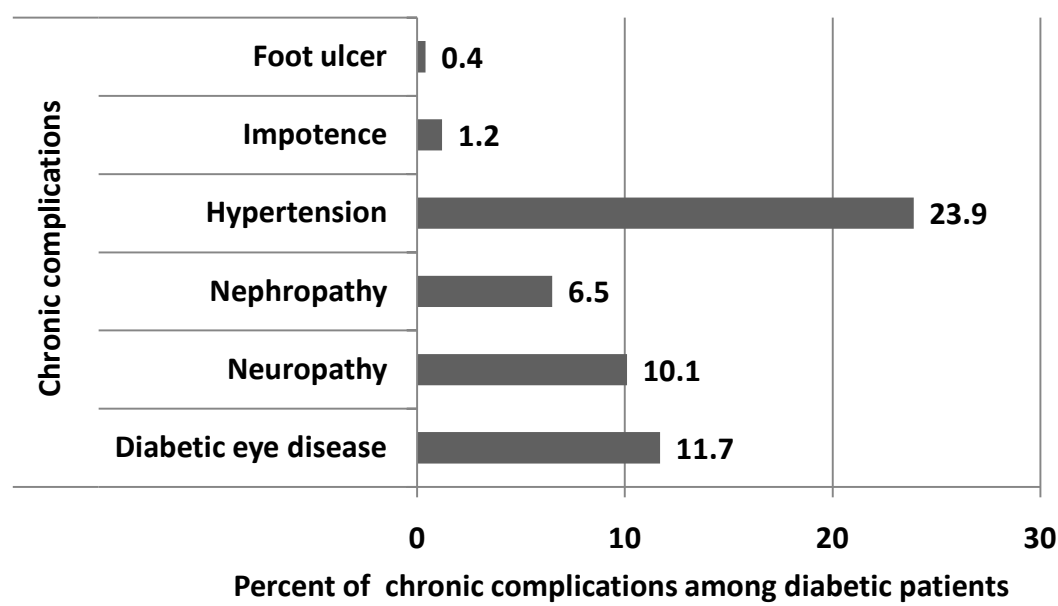

Figure 1. Proportion of chronic complications among diabetic patients at Nigist Eleni Mohammed Memorial Hospital, Hossana, South Ethiopia, 2013.

Hypertension was found in $23.9 \%$ of diabetic patients. Similar finding was reported from Hawassa and Jimma University Hospitals, Ethiopia [8] [27]. But different from another study conducted in Jimma University hospital, Ethiopia 64.1\% [11]. This might be to the fact that our study was based on patient chart review and the other used primary data.

The proportion of neuropathy $10.1 \%$ and nephropathy $6.5 \%$ obtained in this study were in agreement with a study done at yekatit 12 hospital, Ethiopia [19]. Similar finding for neuropathy was also reported from a study done at Tikur anbesa and St. Paul's hospitals, Ethiopia 12.4\% [20].

Diabetic eye disease was documented among $11.7 \%$ of diabetic patients. This finding was less compared to studies done in Jimma, which was 33.8\% [8] and Menilik II hospital 31.4\% [23]. However in Africa the preva- 
lence of retinopathy ranged from $7 \%$ in Kenya to $63 \%$ in South Africa [2]. The lower prevalence in this study could be due to the difference in duration of diabetes. Majority of the participants had $<5$ year duration of diabetes in the current study. It was indicated that microvascular complications of diabetes are less common in the first five years of diabetes duration [4].

Compared to age group of 15 - 29 year diabetics there was higher risk of chronic complications for those who were in age groups of 45 - 64 and $\geq 65$ year diabetics. This finding is congruent with studies done in china, Libya and camerone [13]-[15]. And this study showed, diabetic patient with $>10$ year duration since the time of diabetes diagnosis were 2.87 times more likely to develop chronic complications than those $<5$ years duration of diabetes. The increase in visceral adiposity with age is associated with the rise in insulin resistance [4]. Thus it results in uncontrolled glycemia which is responsible for diabetes related complications [14]. However, in our study neither fasting blood sugar nor central obesity which measure visceral adiposity by waist to hip circumference ratio was significantly associated with chronic complications and none of the participants in this study had Glycosylated hemoglobin $\left(\mathrm{Hb}_{\mathrm{Ic}}\right)$ determination even if it is recommended by American diabetes association (ADA) two times a year [27].

The current study revealed that diabetic patients who did not perform self-monitoring of blood glucose were 15.22 times more likely to have chronic complication than those who performed self-monitoring of blood glucose. A retrospective cohort study conducted in Germany has shown similar finding, in which diabetic patients in non-SMBG subgroup were associated with chronic complications [26]. According to the American diabetes association, Self-monitoring of blood glucose (SMBG) have a key role in maintaining specific glycemic goals and recommends daily self-monitoring of blood glucose [27]. Various studies also support this recommendation, in which SMBG has been shown to be associated with better glycemic control, improved medication compliance and increased frequency of visit to health institution [26]. However, controversial result was reported from Italy where SMBG frequency $\geq 1$ time per day has been shown significantly associated with higher Glycosylated hemoglobin $\left(\mathrm{HbA}_{\mathrm{Ic}}\right)$, distress, worries and depressive symptoms in non-insulin treated diabetic patient [28]. In fact our study participants perform SMBG once per week and most of them were insulin treated diabetic patients. Despite small sample size of this study, our finding suggests that not performing SMBG is a risk factor for chronic complication after controlling for non-insulin and insulin treated diabetic patients.

Our study has some limitation and hence interpretation of the results needs certain consideration. Chronic complications, type of diabetes and fasting blood sugar data's were collected retrospectively and incompleteness of patent charts was one of the short coming of this study. Most diabetic patients particularly type II diabetics develop chronic complication before the time of diabetes diagnosis and we can't relate duration of diabetes and chronic complication because of lead time bias. But the result suggests that long history of diabetes duration is risk factor for chronic complication. Self-care practice was measured using Summary diabetes self-care activity measurement tool which has acceptable reliability and validity. However not validated locally might lead to misclassification and subjected to subjective response and recall bias.

\section{Conclusion}

Overall, about $46.2 \%$ of diabetic patients had chronic complications. Hypertension, diabetes related eye disease, neuropathy and nephropathy were the major chronic complications among diabetic patients. Age between 45 64 and $\geq 65$ years, $>10$ year duration of diabetes and not performing self-monitoring of blood glucose were strongly associated with chronic complications. Prevention and management of chronic complications in diabetic patients should primary target age groups of $45-64$ and $\geq 65$ years and those with $>10$ year duration of diabetes through strengthening early diagnosis and improving case management. Diabetes education should focus on health benefit of self-monitoring of blood glucose and improving diabetes education strategy on self-monitoring of blood glucose needs special warrant.

\section{References}

[1] Sarah, W., Gojka, R., Anders, G., Richard, S. and Hilary, K. (2004) Global Prevalence of Diabetes, Estimates for the Year 2000 and Projections for 2030. Diabetes Care, 27, 1047-1053. http://dx.doi.org/10.2337/diacare.27.5.1047

[2] Sicree, R., Shaw, J. and Zimmet (2009) The Global Burden: Diabetes and Impaired Glucose Tolerance. Diabetes Atlas, IDF. 4th Editions. International Diabetes Federation, Brussels.

[3] Ducorps, M., Ndong, W., Jupkwo, B., Belmejdoud, G., Poirier, J.M., Watkins, P. and Alemu, S. (2003) Delivery of 
diabetes care in Ethiopia: An experience from Gondar. Ethiopian Medical Journal, 41, 9-17.

[4] Kasper, L. (2010) Harrison’s Principle of Internal Medicine. Chapter 344. 18th Edition. McGrew-Hill Companies, New York City.

[5] Victoria, H. and Reimar, W. (2011) Ole H and Nicolai L. Diabetes in Sub Saharan Africa 1999-2011: Epidemiology and Public Health Implications. A Systematic Review. BMC Public Health, 11, 564. http://dx.doi.org/10.1186/1471-2458-11-564

[6] Feleke, Y. and Enquselassie, F. (2005) An Assessment of the Health Care System for Diabetes in Addis Ababa. Ethiopian Journal of Health Development, 19, 203-210.

[7] Seyum, B., Mengistu, Z. and Berhanu, P. (2001) Retinopathy in Tikur Anbessa Hospital Diabetic Clinic. Ethiopian Medical Journal, 39, 123-31.

[8] Dawit, W., Leja, H., and Kifle, W. (2010) Patterns of Diabetic Complications at Jimma University Specialized Hospital, Southwest Ethiopia. Ethiopian Journal of Health Sciences, 20, 33-39.

[9] Seyum, B. (1998) Impotence in Ethiopian Diabetic Men. East African Medical Journal, 75, 208-210.

[10] Mengistu, M. (1987) The Pattern of Chronic Complications in Adult Ethiopian Diabetics. Ethiopian Medical Journal, 25, 167-176.

[11] Gudina, E.K., Amade, S.T., Tesfamichael, F.A. and Ram, R. (2011) Assessment of Quality of Care Given to Diabetic Patients at Jimma University Specialized Hospital Diabetes Follow-Up Clinic, Jimma, Ethiopia. BMC Endocrine Disorders, 11, 19. http://dx.doi.org/10.1186/1472-6823-11-19

[12] Feleke, Y. and Enquselassie, F. (2007) Cost of Hospitalization of Diabetic Patients Admitted at Tikur Anbessa Specialized Hospital, Addis Ababa, Ethiopia. Ethiopian Medical Journal, 45, 275-282.

[13] Tamba, S.M., Ewane, M.E., Bonny, A., Nkidiaka Muisi, C., Nana, E., Ellon, A., Mvogo, C.E. and Mandengue, S.H. (2013) Micro and Macrovascular Complications of Diabetes Mellitus in Cameroon: Risk Factors and Effect of Diabetic Check-Up-A Monocentric Observational Study. Pan African Medical Journal, 15, 141. http://dx.doi.org/10.11604/pamj.2013.15.141.2104

[14] Liu, Z.L., Fu, C.W., Wang, W.B. and Xu, B. (2010) Prevalence of Chronic Complications of Type 2 Diabetes Mellitus in Outpatients-A Cross-Sectional Hospital Based Survey in Urban China. Health and Quality of Life Outcomes, 8, 62. http://www.hqlo.com/content/8/1/62 http://dx.doi.org/10.1186/1477-7525-8-62

[15] Roaeid, R. and Kadiki, O. (2011) Prevalence of Long-Term Complications among Type 2 Diabetic Patients in Benghazi, Libya. Journal of Diabetology, 3, 5.

[16] Orchard, T.J., Dorman, J.S., Maser, R.E., Becker, D.J., Drash, A.L., Ellis, D., LaPorte, R.E. and Kuller, L.H. (1990) Prevalence of Complications in IDDM by Sex and Duration: Pittsburgh Epidemiology of Diabetes Complications Study II. Diabetes, 39, 1116-1124. http://dx.doi.org/10.2337/diab.39.9.1116

[17] Giday, A., Wolde, M. and Yihdego, D. (2010) Hypertension, Obesity and Central Obesity in Diabetics and Non-Diabetics in Southern Ethiopia. Ethiopian Journal of Health Development, 24, 145-147.

[18] Nigist Eleni Mohammed Memorial Hospital, 9 Month Activity Report, 2012/2013, Unpublished.

[19] Lester, F.T. (1984) The Clinical Pattern of Diabetes Mellitus in Ethiopians. Diabetes Care, 7, 6-11. http://dx.doi.org/10.2337/diacare.7.1.6

[20] Adem, A., Demis, T. and Feleke, Y. (2011) Trend of Diabetic Admissions in Tikur Anbessa and St. Paul's University Teaching Hospitals from January 2005-December 2009, Addis Ababa, Ethiopia. Ethiopian Medical Journal, 49, 231238.

[21] WHO, Waist Circumference and Waist-Hip Ratio: Report of a WHO Expert Consultation. Geneva, 2008.

[22] Deborah, J., Sarah, E. and Russell, E. (2000) The Summary of Diabetes Self-Care Activities Measure: Results from 7 studies and a revised scale. Diabetes Care, 23, 943-950.

[23] Ejigu, A. (2000) Pattern of Chronic Complication of Diabetic Patients in Menilik II hospital, Ethiopia. Ethiopian Journal of Health Development, 14, 113-116.

[24] Struijs, J.N., Baan, C.A., Schellevis, F.G., Westert, G.P. and van den Bos, G.A.M. (2006) Comorbidity in Patients with Diabetes Mellitus: Impact on Medical Health Care Utilization. BMC Health Services Research, 6, 84. http://dx.doi.org/10.1186/1472-6963-6-84

[25] Kerr, E.A., Heisler, M., Krein, S.L., Kabeto, M., Langa, K.M., Weir, D. and Piette, J.D. (2007) Beyond Comorbidity Counts: How Do Comorbidity Type and Severity Influence Diabetes Patients’ Treatment Priorities and Self-Management? Journal of General Internal Medicine, 22, 1635-1640. http://dx.doi.org/10.1007/s11606-007-0313-2

[26] Martin, S., Schneider, B., Heinemann, L., Lodwig, V., Kurth, H., Kolb, H. and Scherbaum, W. (2006) Self-Monitoring 
of Blood Glucose in Type 2 Diabetes and Long-Term Outcome: An Epidemiological Cohort Study. Diabetologia, 49, 271-278. http://dx.doi.org/10.1007/s00125-005-0083-5

[27] American Diabetes Association (2003) Tests of Glycemia in Diabetes. Diabetes Care, 27, s91-s93.

[28] Franciosi, M., Pellegrini, F., De Berardis, G., Belfiglio, M., Cavaliere, D., Di Nardo, B., Greenfield, S., Kaplan, S.H., Sacco, M., Tognoni, G., Valentini, M. and Nicolucci, A. (2001) The Impact of Blood Glucose Self-Monitoring on Metabolic Control and Quality of Life in Type 2 Diabetic Patients. Diabetes Care, 24, 1870-1877.

http://dx.doi.org/10.2337/diacare.24.11.1870 